\title{
The potential toxic side effects of flavonoids
}

\author{
ZhimeI TANG; QIANG ZHANG* \\ School of Biology and Food Engineering, Guangdong University of Petrochemical Technology, Maoming, 525000, China
}

Key words: Flavonoids, Food supplements, Toxicity, Safety assessment

\begin{abstract}
Flavonoids are a class of phytochemical molecules abundant in many plants, fruits, vegetables, and leaves. Flavonoids possess a series of significant biological activities, including anticancer, antioxidant, antiviral, and antiinflammatory properties. They become an important source of dietary supplements and natural health products. Though many studies confirmed the safety of flavonoids, the potential toxicity of flavonoids is still a remarkable field of research to be explored. The enthusiasm for flavonoids expressed by the public has sometimes overlooked their toxicity and also consumed the flavonoids exceeding the body requirements. The current review focused on the potential toxicity of flavonoids to make the public consume flavonoids with caution. This review summarizes the current toxicity which has been reported in vivo and in vitro experiments. The toxicity involves carcinogenicity and mutation, liver and kidney toxicity, and the influence on the thyroid and reproductive function and intestinal flora disorders. The mechanism of toxicity is fully complicated, and current evidence indicates that natural flavonoid glycosides act on different targets with different doses in vivo and in vitro experiments. Though most kinds of flavonoids are considered safe, flavonoids proposed as food supplements need to be assessed their tolerable upper intake level as there have been reports of toxic flavonoids.
\end{abstract}

\section{Introduction}

Flavonoids are a large number of small molecules abundant in fruits, vegetables, and legumes. It has been widely known for centuries that derivatives of plant origin have a broad spectrum of biological activity (Jin, 2019; Martins et al., 2019). Evidence provided suggestions that flavonoids play an important role in chronic disease prevention and viral diseases treatment through a multi-factorial action involving the antioxidant, anti-inflammatory, and other biological activities (Niedzwiecki et al., 2016; Pal and Konkimalla, 2016; Pandey et al., 2017; Volobuff et al., 2019, Istifli et al., 2020). They have a lot of beneficial effects associated with some chronic diseases such as cancer, Alzheimer's disease (AD), and atherosclerosis (Burke et al., 2018; Liu et al., 2017; Szczechowiak et al., 2019; Zhang et al., 2019). Flavonoids have attracted more enthusiasm from scientists and the public in the development and utilization of natural medicines for their broad spectrum of biological activity and low toxicity. Thus, some people widely consume flavonoids, particularly referred to as plant isoflavones, as dietary supplements and natural health products exceeding the usual

*Address correspondence to: Qiang Zhang, zhangqiang@gdupt.edu.cn Received: 26 January 2021; Accepted: 16 March 2021 dietary intake levels (Jucá et al., 2020). In this condition, the concentration of flavonoids in humans is higher than the normal amount of that from the consumption provided by conventional intake. As we all know, compelling data have shown that the consumption of flavonoids can cause adverse health effects if the doses consumed exceed the threshold. Surprisingly, many studies also proved that low doses of these compounds have the potential for adverse effects. Although in this condition many biological effects published in a great number of scientific studies based on in vitro experiments, as well as animal and human studies declared the safety of the flavonoids, the potential toxicity found among the safety evaluation of flavonoids should be paid with caution. Our aim in this review was to present an overview of the reports in which the toxic side effects and the possible risk when exposed to flavonoids. Hence, we thoroughly analyzed many original articles in the process of our literature search and found the possible potential toxicity involves carcinogenicity, liver toxicity, and the influence on the thyroid function and reproductive system, the intestinal flora disorder, and neurological abnormalities.

\section{Carcinogenicity}

A great number of studies have shown that flavonoids negatively correlate with cancer (Chang et al., 2018; Nimptsch et al., 2016). Recent case-control research that 
analyzed 1522 breast cancer patients in Chinese women revealed that there was an inverse correlation between the risk of breast cancer and the intake of total flavonoids (Feng et al., 2020). Phytoestrogens are particularly demonstrated in that they have the capacity of protecting against breast cancer and other hormone-related cancers. However, it is interesting to find that many flavonoids can still induce cell mutation and promote tumor cell proliferation in in vitro and animal experiments. Due to the large species of flavonoids, the mechanisms of their carcinogenesis are still not clear and need further exploration. It is also notable that some flavonoids such as phytoestrogen can exert biphasic effects in some tumor cell lines with different doses (Jodynis-Liebert and Kujawska, 2020).

Previous studies have shown that genistein can promote the proliferation of estrogen-dependent MCF-7 cells at low concentrations and is cytostatic at higher concentrations (Kabała-Dzik et al., 2018; Limer et al., 2006). These findings were consistent with another animal experiment in which MCF-7 cells were implanted in ovariectomized mice. The possible mechanism explored by the authors is probably that genistein is related to the estrogen receptor pathway in MCF-7 cells. There is also an animal experiment also showed daily intake of genistein $(250 \mathrm{mg} / \mathrm{kg}$ diet $)$ enhanced an aggressive progression of prostate cancer in transgenic adenocarcinoma mouse prostate mice, while consumption of a higher dose of $1000 \mathrm{mg} / \mathrm{kg}$ daily did not result in the inhibitory progression of cancer (El Touny and Banerjee, 2009). The mechanism suggested that it could enhance the proliferative and metastatic early-stage prostate cancer in an estrogen-and phosphatidylinositol 3 kinases (PI3K)dependent pattern. It was also found that daidzein also influenced the proliferation of T-47D breast cancer cell lines in biphasic dose-dependent ways (Murata et al., 2004). At low concentrations it could have the ability to promote cell growth and inhibit cell proliferation at a higher concentration of $157 \mathrm{mM}$; the underlying mechanism might be relevant to cell cycle regulatory protein, p53 (Ying et al., 2002). Quercetin was also reported to promote the cells' proliferation in a dose-dependent manner. Low concentrations of quercetin increased the proliferation of the human breast cancer cell lines, MCF-7 SH and MCF-7 WT (Miodini et al., 1999; Wu et al., 2018). The possible mechanism in in vitro experiments involves the reactive metabolites of quercetin oxidation, which influences the formation of DNA and ER-dependent pathways (Andres et al., 2018; Rietjens et al., 2005; van der Woude et al., 2005). Interestingly two previous studies in vivo revealed that quercetin could promote carcinogenesis in rodents (Singh et al., 2010; Zhu and Liehr, 1994). The experiment showed that male hamsters with quercetin daily intake for around 6 months caused an increase in kidney tumor $(>5 \mathrm{~mm})$ and abdominal metastases compared to the control group (Zhu and Liehr, 1994). The other study reported enhanced cell proliferation and the tumor latency of mammary glands by quercetin at a low dose daily intake in female rats for 8 months compared to the control group (Singh et al., 2010). Although some phytoestrogen is reported to have the ability to act on the biphasic dose-response ways, many pieces of evidence suggest flavonoids have the biological activity of anticancer. Though the experiments mentioned above revealed that some kind of flavonoids could induce tumor development with the application of different doses, there is still lacking the convincing evidence it could act in a biphasic pattern in the human condition.

\section{Hepatotoxicity and nephrotoxicity}

Though many data have also confirmed that flavonoids have exhibited significant liver-protection and renal-protection properties in vitro and in vivo (Kandemir et al., 2020; Levin et al., 2019; Levin et al., 2016; Papackova et al., 2018), few studies also showed the potential hepatotoxicity and nephrotoxicity with epigallocatechin gallate (EGCG) intake (James et al., 2015; Lambert et al., 2010; Levin et al., 2019; Levin et al., 2016). The underlying mechanism of flavonoids is not clear but could be proposed that the transitory intake results in oxidative stress leading to liver and kidney injury under high-dose conditions. The results indicated that plasma alanine aminotransferase (ALT) increased and the survival rate reduced by $85 \%$ after a single dose of EGCG $(1500 \mathrm{mg} / \mathrm{kg})$ in male CF-1 mice, moderate to severe hepatic necrosis was also found following treatment with EGCG (750 mg/kg) (Lambert et al., 2010). A serial of experiments has indicated that the underlying mechanisms of hepatotoxic effects of EGCG are correlated with the increasing use of green tea dietary supplements, which may probably cause an inflammatory cascade that leads eventually to hepato-toxicity (Hu et al., 2018; James et al., 2018; Wang et al., 2015). Similar results were also observed in Beagle dogs treated with Polyphenon E, a kind of tea polyphenol mixture that contained 60\% EGCG (Swezey et al., 2003). There are many case reports relevant to human hepatotoxicity for the consumption of green tea-containing products. A randomized, double-blind clinical trial in Germany demonstrated that two patients in the group treated with epigallocatechin gallate had to remove from the experiment because of hepatotoxicity. The doses of more than $1200 \mathrm{mg}$ intake daily may be used with caution (Levin et al., 2019). EGCG was overall well tolerated in the other 45 patients, these inconsistent results revealed that genetic and/or lifestyle factors may play an important role in susceptibility to EGCG-mediated hepatotoxicity.

It is previously reported that EGCG caused nephrotoxicity in vivo experiments, as exhibited by increases in serum creatinine, the most important biomarker of nephropathy (Fatima et al., 2016; Fatima et al., 2015; Rasheed et al., 2017). The underlying mechanism was probably that high-dose EGCG impairs kidney functions through the suppression of antioxidant enzymes and heatshock protein expressions, which might augment oxidative stress (Inoue et al., 2011). The recent study indicated that EGCG (100 mg/kg/day) would result in a deteriorated oxidative stress condition in streptozotocin-induced diabetic mice. Histopathological examination also confirmed EGCG caused renal injury in diabetic mice (Rasheed et al., 2017). However, whether EGCG-induced nephrotoxicity is doserelated remains to be determined, some authors suggested that the administration duration be one of the crucial factors in the course of EGCG-induced toxicity. Therefore, though many studies have demonstrated the EGCG has the biological activity of mitigating or preventing diabetes, 
patients with diabetes are still advised to consume EGCG as dietary supplements with caution.

Quercetin is another kind of flavonoid that is relevant to nephrotoxicity. There was an important study conducted by the US National Toxicology Program (NTP) about the safety evaluation of quercetin (National Toxicology Program, 1992). In this study, groups of 50 male and female rats were treated with 0, 1000, 10000, or $40000 \mathrm{ppm}$ quercetin ( $>95 \%$ pure) in feed for 104 weeks. The results showed chronic nephropathy and increased incidence of kidney adenomas were observed in high dose-related male rats. There was no obvious kidney injury in female rats with quercetin intake. Hard et al. (2007) re-evaluated the renal histopathology in Fischer 344 rats and confirmed that the similar increase in renal tumors in mid- and high-dose males rats (Hard et al., 2007). They also found that nephropathy was already promoted by the high quercetin dose from the intervention of 6 months. Based on the above studies in rats, the question is proposed whether quercetin could aggravate the underlying renal deleterious processes with a high dose of quercetin consumption not only in animals but also in human beings. Though there are no valuable adverse effect of quercetin on kidney function found in human intervention studies, we should consider cautious interpretation when quercetin was consumed by people with renal failure (Andres et al., 2018)

\section{Thyroid toxicity}

The effect of flavonoids on thyroid toxicity involves many factors, such as the duration of intake and the realistic exposure conditions. Though many studies in vivo and in vitro have demonstrated that many kinds of flavonoids can interfere with thyroid function and metabolism (Baldissarelli et al., 2016; Bennetau-Pelissero, 2016; Giuliani, 2019; HabzaKowalska et al., 2019), the explicit mechanism is much complicated and needs to be further explored. Although many flavonoids can interfere with thyroid function, phytoestrogens are the most concerning substances influencing thyroid function and metabolism. Many studies have reported that phytoestrogens and quercetin could have possible thyroid-disruptive properties.

Soy and soy foods are the most common nutritional substances of phytoestrogens; they are rich in high protein content and often act as the production of meat analogs and milk substitutes for some vegetarians and some kids allergic to milk. Most researches about thyroid toxicity are isoflavones of soy components, which have estrogenic properties highly contained in soybeans (Rizzo and Baroni, 2018). Soy isoflavones are reported to be involved in the whole process of thyroid hormone metabolism. They can act as competitive substrates to affect the ionization process and further change the activity of TPO enzyme and TTR binding proteins (Hüser et al., 2018; Renko et al., 2015; Sathyapalan et al., 2011; Šošić-Jurjević et al., 2014). The iodinated isoflavones were detected in human urine after consumption with isoflavonoids. Some studies found that genistein and other related flavones could inhibit the binding of TTR to $\mathrm{T}_{4}$ and $\mathrm{T}_{3}$. Thus, they may alter the kinetics and distribution of thyroid hormones in the body.
The most interesting finding is different targets are found in the different animal models concerning the influence on the thyroid system. A study in rats reported that the consumption of a standard soy-based rodent diet reduced TPO activity in rats by approximately $50 \%$ compared to a soy-free diet (Šošić-Jurjević et al., 2017). Silverstein et al. (2014) found that ovarian function influenced thyroid function through the effects of isoflavones in adult female cynomolgus monkeys (Silverstein et al., 2014). It has been assumed that altered sexual hormones also have an influence on the synthesis and stability of serum thyroid hormone distribution proteins through the regulation of the hypothalamic-pituitary-thyroid axis.

In human studies, it was found that flavonoids could intervene with many key processes to affect thyroid function (D'Adamo and Sahin, 2014; Hüser et al., 2018; Nakamura et al., 2017; Sathyapalan et al., 2011). Under conditions of iodine deficiency, the published results supported an association between an increased risk of developing goiter. The incidence of autoimmune thyroid disease in children after early fed with powdered milk containing soybean was significantly higher than that of the control group, especially in the iodine deficiency (Andersson et al., 2007). Importantly, human observational and interventional studies indicated if the iodine intake is adequate, the consumption of soy-based foods is unlikely to hurt the thyroid gland system in healthy humans (Andres and Lampen, 2013). The data also showed that there were no significant adverse effects observed in adult subjects after consumption of abundant soybean protein rich in isoflavone (Tonstad et al., 2016; Xiao et al., 2014). Another study also reported that the plasma concentration of free triiodothyronine $\left(\mathrm{FT}_{3}\right)$ decreased slightly and did not cause any discomfort to postmenopausal females after $30 \mathrm{~g}$ soy protein powder intake for 8 weeks (Persiani et al., 2016).

\section{Estrogen activity of phytoestrogens}

Phytoestrogens have the potential hormone-like activities because of their diphenolic ring, which makes them have the ability to bind ER receptors (Smith et al., 2020). Daidzein and genistein are two predominant types of soy isoflavones in daily intake. Though daidzein and genistein with weakly estrogenic activities have been reported to be approximately $10^{-2}$ to $10^{-3}$ fold less potent than endogenous estrogen (Mortensen et al., 2009), excessive or improper intake may also lead to the disorder of hormone metabolism and endocrine function (Cederroth et al., 2012; Hamilton-Reeves et al., 2010). Concerning the safety of soy isoflavones of hormone-like activities, the later reproductive health outcomes in infants fed with soy isoflavones and the potential risk of cancer in adults are the main concepts that should be taken into consideration.

Soy protein-based infant formula (SBIF) is the only alternative for infants allergic to cow's milk-based formula, diarrhea due to lactose intolerance (Merritt and Jenks, 2004). Infant exposure to soy formula often lasts from birth to one year of life, an important stage of development that is particularly sensitive to dietary intake. Several countries have restricted the consumption of soy protein-based infant formula because of the concern with the safety of early 
isoflavone exposure in infants and the following reproductive system development (McCarver et al., 2011). Though many data showed that the number of isoflavones intake in infants was much less than that in normal infants, there is still concern regarding the infants fed with SBIF (Dinsdale and Ward, 2010). Though several animal experiments data showed only slight adverse effects in rats with early exposure to soy isoflavones (Badger et al., 2002; Cederroth et al., 2010; Kaludjerovic et al., 2012; Klein et al., 2002), only very few studies have traced the outcome on reproductive health at adulthood, it is not sure whether SBIF has some correlation with detrimental effects on reproductive health at adulthood (Strom et al., 2001; Zhao et al., 2019). Indisputably there are a lot of considerations that need to be taken into in the course of analysis of the findings from animal models to humans. Many animal experiments have demonstrated that isoflavones have different outcomes on the reproductive system and sexual development of male and female animals in adulthood after long-term exposure to soy isoflavone.

The research on female animals mainly focused on mammary gland development, sexual maturation, and endocrine function. Some studies have suggested that early exposure be likely to enhance the differentiation of the mammary gland and further reduce the potential cancer risk (Blei et al., 2015; Kakehashi et al., 2012; Santos et al., 2016). Some data shows that female rats treatment with genistein resulted in fewer terminal end buds and advanced development and ductal elongation which was related to the lower mammary cancer risk (Blei et al., 2015; Rimoldi et al., 2007). The mechanism by which genistein influences mammary gland maturation and development needs to be further explored. The other reproductive organ worthy of attention is the uterus that is also sensitive to early isoflavone exposure. Neonatal mice treated with genistein had greater uterine gland number and increased uterine weight and epithelial cell height (Jefferson et al., 2002; Jefferson et al., 2009). Another experiment data also showed there is a higher incidence of absence in the uterine corpora lutea in female mice after intervention with genistein (Jefferson et al., 2011). While some data showed that daidzein did not cause any abnormity in the uterus, suggesting that daidzein may not have a measurable estrogenic effect on the mouse uterus, implying that daidzein may not have a similar estrogenic effect on the mouse uterus (Jarić et al., 2018; Zhang et al., 2018). The most important factor in the animal study is serum levels of soy isoflavone exposure in the neonatal mouse model resemble those of human infants, which attracts people's attention to ovarian development in adults. The studies on the male animal model mainly have involved male sexual maturation of the reproductive system and fertility (Cederroth et al., 2010; Robertson et al., 2002; Ronis et al., 2018; Yatkin et al., 2007). An influential study was that twin marmoset monkeys which evoke many European countries' attention and reduce the daily dosage of SBIF (Sharpe et al., 2002). In this study, one twin was fed with SBIF from the beginning of day four or five of life. The serum testosterone of marmoset treated with SBIF had consistently reduced compared with its twin-fed cow milk formula. What is notable was that the dose of monkey's daily intake was about $1.6-3.5 \mathrm{mg}$ isoflavones/kg body weight, which is less than half the exposure level of a human infant SBIF intake. While the consequent study demonstrated normal fertility and progression of puberty in the same subject group and feeding protocol (Tan et al., 2006). Some people still concern about whether there is a relation between the declining sperm count occurring among men and soy isoflavone exposure (Mumford et al., 2015). Two metaanalyses confirmed that neither soy nor isoflavone intake affects total or bioavailable circulating testosterone concentrations in men (Hamilton-Reeves et al., 2010; Reed et al., 2020). Based on the data gathered from animal and human studies, there seem to draw such conclusions that no obvious effect on sexual maturity in males. The experiment data showed that exposure did not affect preputial separation, fertility, sperm count, and testosterone levels with high oral doses of soy isoflavone treatment (Cederroth et al., 2010; West et al., 2005).

Currently, there is still a debate regarding whether the physiological impact of soy isoflavone consumption influences infants (Reed et al., 2020; Zou et al., 2020). Though several published studies and case reports describing feminizing effects, including reduced testosterone levels in men, recently, a meta-analysis including 41 studies showed that either soy or isoflavone intake affects male reproductive hormones (Reed et al., 2020). A longitudinal prospective study is needed to show that the timing of exposure may modulate effects of later health, and it will be of great importance to further take the influence on reproductive outcomes at later stages of development into consideration.

\section{Affecting gut microbiota, and neurobehavioral disorders}

Recent studies reported that consumption of some kinds of flavonoids, especially genistein and daidzein influenced the gut microbial flora (Matthies et al., 2012; Vázquez et al., 2017; Wyns et al., 2010). There are still many differences in experiments between the animal model and human beings; the data showed that there were close correlations between diet-responsive intestinal metabolites and gut microbes in soy-fed neonatal pigs (Piccolo et al., 2017). In this study, the author suggested that bacteria species diversity and a greater percentage of cyanobacteria within the duodenum of sowfed pigs are related to dietary intake. Another study also showed that a soy formula diet affected the intestinal epithelial lining, microbial populations, and intestinal epithelial barrier as well as anti-inflammatory markers (Yeruva et al., 2016). The studies in human beings also demonstrated that phytoestrogen consumption or exposure might also influence the gut microbe composition (Yoshikata et al., 2018; Iino et al., 2019; Smith-Brown et al., 2016; Wu et al., 2016). The study showed that soy intake dosage was associated with the number of equol-generating bacteria within the intestine among Asian populations (Yoshikata et al., 2018). Another study found that the gut microbial flora was surprisingly quite similar between the vegans consuming a soy-rich diet and the omnivores groups (Wu et al., 2016). Though daidzein and genistein of plasma metabolome were predictably elevated in vegans relative to omnivores, equal concentrations did not differ between the 
two groups of individuals. These findings suggest that a vegan or soy-rich diet perhaps alters gut bacteria-derived metabolism but not necessarily the gut microbiota themselves.

It is also being recognized that the gut microbiome can affect the host's neurobehavioral state, which has been hypothesized to be related to the microbiome-gut-brain axis (Alò et al., 2019; Marshall et al., 2019; Kolatorova et al., 2018; Rosenfeld, 2015). The first solid evidence relevant to gut microbiota disturbances with neurobehavioral disorders is related to germ-free (GF) mice that lack a resident gut microbiome (Sudo et al., 2004). GF mice are more anxious, less exploratory, and show cognitive and social deficits. These findings suggest that there is, probably, a crosstalk between the gut microbiota and brain with bacteria. A study revealed that early exposure to GEN could also cause behavioral abnormalities such as increased defensive behaviors and decreased aggressive behaviors in male C57BL/6 mice (Wisniewski et al., 2005). Another study demonstrated that the male offspring of the CD1 mice had significant changes in anxiety and aggressive behaviors in adults after the mice's daily exposure of dams to genistein (100 $\mu \mathrm{g} / \mathrm{g}$ of body weight) during late pregnancy and early lactation (Rodriguez-Gomez et al., 2014). Westmark reported that there may be a potential linkage between feeding infant soy formula and subsequent risk for autistic behaviors in autistic children (Westmark, 2013). Additional data from this cohort revealed that febrile seizures in autistic boys and girls might be related to soy-based formulas (Westmark, 2014). The current study emphasizes the correlation analysis between gut metabolite changes produced by the bioactive forms of the flavonoids and behavioral responses. The underlying mechanism of the microbiome-gut-brain axis is still unclear and needs to be further explored.

\section{Conclusions and Recommendations}

We reviewed the available evidence on the potential toxicity of flavonoids. In the study of the relationship between flavonoids and human health, there are still many contradictions among cell culture, animal models, human experiments, and epidemiological investigation. Flavonoids extracts are often used in cell culture or animal models, while foods with abundant flavonoids such as soybean are often used in human experiments. Due to the complexity of the food composition and its decomposition into other metabolites in the digestive system, the observed results are likely to have the effect of other ingredients. We know the results were also influenced by many factors, such as the design of the experiment, the selection of subjects, and the effect of observation cases. Especially inhuman experiments, many factors are difficult to control. Therefore, there are still great limitations in inferring the possible consequences of the human body from the results of human cell culture and animal experiments. Also, the dosage of flavonoids observed in cell culture is dose-dependent, and it is difficult to evaluate the proper concentration in the human body. Combined with the limitations of animal experiments and the limited epidemiological data, it is difficult to conclude the toxic effect of flavonoids on human health. Although many pieces of research have been done, the data in this field about the toxicity is still insufficient. A large number of long-term human studies are still needed to thoroughly demonstrate its clinical effects and to detect its effects on estrogen target tissues, such as the breast and endometrium. At present, the consumption of soybean food and isoflavone supplements is increasing, so it is necessary to study the potential toxicity of these substances. However, there has been little evidence that SBIF and other factors have effects on the reproductive function of infants and young children in adulthood. This delay may prevent researchers from exploring the potential toxicity of SBIF. Considering the above reasons and animal experimental data, it is necessary to study the effect of SBIF on the growth and development of infants and later. Besides, it is necessary to further study the effects of SBIF on animals of different genders, and the reasonable standard dose of soy isoflavone as food and drug intake to the human body in different ages and regions.

Author Contribution: Zhimei Tang reviewed and summarized relevant literature, drafted the first version and reviewed the work in progress. Qiang Zhang constructed the framework of the paper, reviewed the work in progress, and shaped the final draft. Both authors approved the final version of the manuscript.

Funding Statement: This work was supported by grants from the Research Platforms and Projects of Universities in Guangdong Province (2020ZDZX1027), Projects of PhDs' Start-up Research of GDUPT (702-519221), Projects of Talents Recruitment of GDUPT (519030), and from the Outstanding Innovation Team Project of Basic Scientific Research Operating Expenses of Provincial Universities in Heilongjiang Province (2018-KYYWF-0915).

Conflicts of Interest: The authors declare that they have no conflicts of interest to report regarding the present study.

\section{References}

Alò R, Zizza M, Fazzari G, Facciolo RM, Canonaco M (2019). Genistein modifies hamster behavior and expression of inflammatory factors following subchronic unpredictable mild stress. Neuroendocrinology 108: 98-108. DOI 10.1159/000495209.

Andersson M, de Benoist B, Delange F, Zupan J (2007). Prevention and control of iodine deficiency in pregnant and lactating women and in children less than 2-years-old: Conclusions and recommendations of the Technical Consultation. Public Health Nutrition 10: 1606-1611. DOI 10.1017/ S1368980007000092.

Andres S, Lampen A (2013). Dietary isolated isoflavone supplements for peri- and postmenopausal women: Risks and questionable benefits. Bundesgesundheitsblatt-GesundheitsforschungGesundheitsschutz 56: 277-284. DOI 10.1007/s00103-0121604-2.

Andres S, Pevny S, Ziegenhagen R, Bakhiya N, Schäfer B, HirschErnst KI, Lampen A (2018). Safety aspects of the use of quercetin as a dietary supplement. Molecular Nutrition \& Food Research 62: 1700447. DOI 10.1002/mnfr.201700447.

Badger TM, Ronis MJJ, Reza H, Caaig RJ, Soheila K (2002). The health consequences of early soy consumption. Journal of Nutrition 132: 559S-565S. DOI 10.1093/jn/132.3.559S. 
Baldissarelli J, Santi A, Schmatz R, Zanini D, Cardoso AM, Abadalla FH, Thomé GR, Murussi C, Polachini CRN, Delenogare DP, Loro VA, Morsch VM, Schetinger MRC (2016). Quercetin changes purinergic enzyme activities and oxidative profile in platelets of rats with hypothyroidism. Biomedicine \& Pharmacotherapy 84: 1849-1857. DOI 10.1016/j.biopha.2016.10.109.

Bennetau-Pelissero C (2016). Risks and benefits of phytoestrogens: Where are we now? Current Opinion in Clinical Nutrition \& Metabolic Care 19: 477-483. DOI 10.1097/MCO.0000000000000326.

Blei T, Soukup ST, Schmalbach K, Pudenz M, Möller FJ, Egert B, Wörtz N, Kurrat A, Müller D, Vollmer G, Gerhäuser C, Lehmann L, Kulling SE, Diel P (2015). Dose-dependent effects of isoflavone exposure during early lifetime on the rat mammary gland: Studies on estrogen sensitivity, isoflavone metabolism, and DNA methylation. Molecular Nutrition \& Food Research 59: 270-283. DOI 10.1002/ mnfr.201400480.

Burke AC, Sutherland BG, Telford DE, Morrow MR, Sawyez CG, Edwards JY, Drangova M, Huff MW (2018). Intervention with citrus flavonoids reverses obesity and improves metabolic syndrome and atherosclerosis in obese $\mathrm{Ldlr}^{-/}$ mice. Journal of Lipid Research 59: 1714-1728. DOI 10.1194/jlr.M087387.

Cederroth CR, Auger J, Zimmermann C, Eustache F, Nef S (2010). Soy, phyto-oestrogens and male reproductive function: A review. International Journal of Andrology 33: 304-316. DOI 10.1111/j.1365-2605.2009.01011.x.

Cederroth CR, Zimmermann C, Beny JL, Schaad O, Combepine C, Descombes P, Doergee DR, Pralongd FP, Vassalli JD, Nef S (2010). Potential detrimental effects of a phytoestrogen-rich diet on male fertility in mice. Molecular and Cellular Endocrinology 321: 152-160. DOI 10.1016/j.mce.2010.02.011.

Cederroth CR, Zimmermann C, Nef S (2012). Soy, phytoestrogens and their impact on reproductive health. Molecular and Cellular Endocrinology 355: 192-200. DOI 10.1016/j. mce.2011.05.049.

Chang H, Lei L, Zhou Y, Ye F, Zhao G (2018). Dietary flavonoids and the risk of colorectal cancer: An updated meta-analysis of epidemiological studies. Nutrients 10: 950-963. DOI 10.3390/nu10070950.

D'Adamo CR, Sahin A (2014). Soy foods and supplementation: A review of commonly perceived health benefits and risks. Alternative Therapies in Health \& Medicine 20: 39-51.

Dinsdale EC, Ward WE (2010). Early exposure to soy isoflavones and effects on reproductive health: A review of human and animal studies. Nutrients 2: 1156-1187. DOI 10.3390/nu2111156.

Fatima S, Al-Mohaimeed N, Al-Shaikh Y, Tyagi P, Banu N, Hasan S, Arjumand S (2016). Combined treatment of epigallocatechin gallate and Coenzyme Q10 attenuates cisplatin-induced nephrotoxicity via suppression of oxidative/nitrosative stress, inflammation and cellular damage. Food and Chemical Toxicology 94: 213-220. DOI 10.1016/j.fct.2016.05.023.

Fatima S, Al-Mohaimeed N, Arjumand S, Banu N, Al-Jameil N, AlShaikh Y (2015). Effect of pre- and post-combined multidoses of epigallocatechin gallate and coenzyme Q10 on cisplatin-induced oxidative stress in rat kidney. Journal of Biochemical and Molecular Toxicology 29: 91-97. DOI 10.1002/jbt.21671.

Feng XL, Ho SC, Mo XF, Lin FY, Zhang NQ, Luo H, Zhang X, Zhang CX (2020). Association between flavonoids, flavonoid subclasses intake and breast cancer risk: A case-control study in China. European Journal of Cancer Prevention 29: 493-500. DOI 10.1097/CEJ.0000000000000561.
Giuliani C (2019). The flavonoid quercetin induces AP-1 activation in FRTL-5 thyroid cells. Antioxidants 8: 112-123. DOI 10.3390/antiox8050112.

Habza-Kowalska E, Kaczor A, Zuk J, Matosiuk D, Gawlik-Dziki U (2019). Thyroid peroxidase activity is inhibited by phenolic compounds-Impact of interaction. Molecules 24: 27662782. DOI 10.3390/molecules24152766.

Hamilton-Reeves JM, Vazquez G, Duval SJ, Phipps WR, Kurzer MS, Messina MJ (2010). Clinical studies show no effects of soy protein or isoflavones on reproductive hormones in men: Results of a meta-analysis. Fertility and Sterility 94: 9971007. DOI 10.1016/j.fertnstert.2009.04.038.

Hard GC, Seely JC, Betz LJ, Hayashi SM (2007). Re-evaluation of the kidney tumors and renal histopathology occurring in a 2-year rat carcinogenicity bioassay of quercetin. Food and Chemical Toxicology 45: 600-608. DOI 10.1016/j.fct.2006.10.018.

Hu J, Webster D, Cao J, Shao A (2018). The safety of green tea and green tea extract consumption in adults-Results of a systematic review. Regulatory Toxicology and Pharmacology 95: 412-433. DOI 10.1016/j.yrtph.2018.03.019.

Hüser S, Guth S, Joost HG, Soukup ST, Köhrle J, Kreienbrock L, Diel P, Lachenmeier DW, Eisenbrand G, Vollmer G, Nöthlings U, Marko D, Mally A, Grune T, Lehmann L, Steinberg P, Kulling SE (2018). Effects of isoflavones on breast tissue and the thyroid hormone system in humans: A comprehensive safety evaluation. Archives of Toxicology 92: 2703-2748. DOI 10.1007/s00204-018-2279-8.

Iino C, Shimoyama T, Iino K, Yokoyama Y, Chinda D, Sakuraba H et al. (2019). Daidzein intake is associated with equol producing status through an increase in the intestinal bacteria responsible for equol production. Nutrients 11: 433. DOI 10.3390/nu11020433.

Istifli ES, Netz PA, Sihoglu Tepe A, Husunet MT, Sarikurkcu C, Tepe B (2020). In silico analysis of the interactions of certain flavonoids with the receptor-binding domain of 2019 novel coronavirus and cellular proteases and their pharmacokinetic properties. Journal of Biomolecular Structure and Dynamics 24: 1-15. DOI 10.1080/07391102.2020.1840444.

Inoue $\mathrm{H}$, Akiyama S, Maeda-Yamamoto $\mathrm{M}$, Nesumi $\mathrm{A}$, Tanaka $\mathrm{T}$, Murakami A (2011). High-dose green tea polyphenols induce nephrotoxicity in dextran sulfate sodium-induced colitis mice by down-regulation of antioxidant enzymes and heat-shock protein expressions. Cell Stress and Chaperones 16: 653-662. DOI 10.1007/s12192-011-0280-8.

James KD, Forester SC, Lambert JD (2015). Dietary pretreatment with green tea polyphenol, (-)-epigallocatechin-3-gallate reduces the bioavailability and hepatotoxicity of subsequent oral bolus doses of (-)-epigallocatechin-3gallate. Food and Chemical Toxicology 76: 103-108. DOI 10.1016/j.fct.2014.12.009.

James KD, Kennett MJ, Lambert JD (2018). Potential role of the mitochondria as a target for the hepatotoxic effects of (-)-epigallocatechin-3-gallate in mice. Food and Chemical Toxicology 111: 302-309. DOI 10.1016/j.fct.2017.11.029.

Jarić I, Živanovic J, Miler M, Ajdžanović V, Blagojević D, Ristić N, Miloševića V, Nestorović N (2018). Genistein and daidzein treatments differently affect uterine homeostasis in the ovary-intact middle-aged rats. Toxicology and Applied Pharmacology 339: 73-84. DOI 10.1016/j.taap.2017.12.001.

Jefferson WN, Couse JF, Padilla-Banks E, Korach KS, Newbold RR (2002). Neonatal exposure to genistein induces estrogen receptor (ER) $a$ expression and multioocyte follicles in the maturing mouse ovary: Evidence for ER $\beta$-mediated and 
nonestrogenic actions. Biology of Reproduction 67: 12851296. DOI 10.1095/biolreprod67.4.1285.

Jefferson WN, Doerge D, Padilla-Banks E, Woodling KA, Kissling GE, Newbold R (2009). Oral exposure to genistin, the glycosylated form of genistein, during neonatal life adversely affects the female reproductive system. Environmental Health Perspectives 117: 1883-1889. DOI 10.1289/ehp.0900923.

Jefferson WN, Padilla-Banks E, Phelps JY, Gerrish KE, Williams CJ (2011). Permanent oviduct posteriorization after neonatal exposure to the phytoestrogen genistein. Environmental Health Perspectives 119: 1575-1582. DOI 10.1289/ehp.1104018.

Jin YS (2019). Recent advances in natural antifungal flavonoids and their derivatives. Bioorganic \& Medicinal Chemistry Letters 29: 126589. DOI 10.1016/j.bmcl.2019.07.048.

Jodynis-Liebert J, Kujawska M (2020). Biphasic dose-response induced by phytochemicals: experimental evidence. Journal of Clinical Medicine 9: 718-745. DOI 10.3390/jcm9030718.

Jucá MM, Cysne Filho FMS, de Almeida JC, Mesquita DDS, Barriga JRM, Dias KCF, Barbosa TT, Vasconcelos LC, Leal LKAM, Ribeiro JE, Vasconcelos SMM (2020). Flavonoids: biological activities and therapeutic potential. Natural Product Research 34: 692-705. DOI 10.1080/14786419.2018.1493588.

Kabała-Dzik A, Rzepecka-Stojko A, Kubina R, Iriti M, Wojtyczka RD, Buszman E, Stojko J (2018). Flavonoids, bioactive components of propolis, exhibit cytotoxic activity and induce cell cycle arrest and apoptosis in human breast cancer cells MDA-MB-231 and MCF-7-a comparative study. Cellular and Molecular Biology (Noisy-le-grand) 64: 1-10. DOI 10.14715/cmb/2018.64.8.1.

Kakehashi A, Tago Y, Yoshida M, Sokuza Y, Wei M, Fukushima S, Wanibuchi H (2012). Hormonally active doses of isoflavone aglycones promote mammary and endometrial carcinogenesis and alter the molecular tumor environment in Donryu rats. Toxicological Sciences 126: 39-51. DOI 10.1093/toxsci/kfs016.

Kaludjerovic J, Chen J, Ward WE (2012). Early life exposure to genistein and daidzein disrupts structural development of reproductive organs in female mice. Journal of Toxicology and Environmental Health 75: 649-660. DOI 10.1080/ 15287394.2012.688482.

Kandemir FM, Yıldırım S, Kucukler S, Caglayan C, Darendelioğlu E, Dortbudak MB (2020). Protective effects of morin against acrylamide-induced hepatotoxicity and nephrotoxicity: A multi-biomarker approach. Food and Chemical Toxicology 138: 111190 . DOI 10.1016/j.fct.2020.111190.

Klein SL, Wisniewski AB, Marson AL, Glass GE, Gearhart JP (2002). Early exposure to genistein exerts long-lasting effects on the endocrine and immune systems in rats. Molecular Medicine 8: 742-749. DOI 10.1007/BF03402038.

Kolatorova L, Lapcik O, Starka L (2018). Phytoestrogens and the intestinal microbiome. Physiological Research 67: S401S408. DOI 10.33549/physiolres.934022.

El Touny LH, Banerjee PP (2009). Identification of a biphasic role for genistein in the regulation of prostate cancer growth and metastasis. Cancer Research 69: 3695-3703. DOI 10.1158/ 0008-5472.CAN-08-2958.

Lambert JD, Kennett MJ, Sang S, Reuhl KR, Ju J, Yang CS (2010). Hepatotoxicity of high oral dose (-)-epigallocatechin-3gallate in mice. Food and Chemical Toxicology 48: 409-416. DOI 10.1016/j.fct.2009.10.030.

Levin J, Maaß S, Schuberth M, Giese A, Oertel WH, Poewe W, Trenkwalder C, Wenning GK, Mansmann U, Südmeyer M,
Eggert K, Mollenhauer B, Lipp A, Löhle M, Classen J, Münchau A, Kassubek J, Gandor F, Berg D, EgertSchwender S, Eberhardt C, Paul F, Bötzel K, Ertl-Wagner B, Huppertz HJ, Ingrid Ricard I, Höglinger GU (2019). Safety and efficacy of epigallocatechin gallate in multiple system atrophy (PROMESA): A randomised, double-blind, placebo-controlled trial. Lancet Neurology 18: 724-735. DOI 10.1016/S1474-4422(19)30141-3.

Levin J, Maaß S, Schuberth M, Respondek G, Paul F, Mansmann U, Oertel WH, Lorenzl S, Krismer F, Seppi K, Poewe W, Wenning G, Giese A, Bötzel K, Höglinger G (2016). The PROMESA-protocol: Progression rate of multiple system atrophy under EGCG supplementation as anti-aggregationapproach. Journal of Neural Transmission 123: 439-445. DOI 10.1007/s00702-016-1507-8.

Limer JL, Parkes AT, Speirs V (2006). Differential response to phytoestrogens in endocrine sensitive and resistant breast cancer cells in vitro. International Journal of Cancer 119: 515-521. DOI 10.1002/ijc.21863.

Liu L, Nagai I, Gao Y, Matsushima Y, Kawai Y, Sayama K (2017). Effects of catechins and caffeine on the development of atherosclerosis in mice. Bioscience, Biotechnology, and Biochemistry 81: 1948-1955. DOI 10.1080/ 09168451.2017.1364618.

Marshall BL, Liu Y, Farrington MJ, Mao J, Helferich WG, Schenk K, Bivens NJ, Sarma S, Lei Z, Sumner LW, Joshi T, Rosenfeld C (2019). Early genistein exposure of California mice and effects on the gut microbiota-brain axis. Journal of Endocrinology 242: 139-157. DOI 10.1530/JOE-19-0214.

Martins BT, Correia da Silva M, Pinto M, Cidade H, Kijjoa A (2019). Marine natural flavonoids: chemistry and biological activities. Natural Product Research 33: 3260-3272. DOI 10.1080/ 14786419.2018.1470514.

Matthies A, Loh G, Blaut M, Braune A (2012). Daidzein and genistein are converted to equol and 5-hydroxy-equol by human intestinal Slackia isoflavoniconvertens in gnotobiotic rats. Journal of Nutrition 142: 40-46. DOI 10.3945/jn.111.148247.

McCarver G, Bhatia J, Chambers C, Clarke R, Etzel R, Foster W, Hoyer P, Leeder JS, Peters JM, Rissman E, Rybak M, Sherman C, Toppari J, Turner K (2011). NTP-CERHR expert panel report on the developmental toxicity of soy infant formula. Birth Defects Research Part B: Developmental \& Reproductive Toxicology 92: 421-468. DOI 10.1002/bdrb.20314.

Merritt RJ, Jenks BH (2004). Safety of soy-based infant formulas containing isoflavones: The clinical evidence. Journal of Nutrition 134: 1220S-1224S. DOI 10.1093/jn/134.5.1220S.

Miodini P, Fioravanti L, Di Fronzo G, Cappelletti V (1999). The two phyto-oestrogens genistein and quercetin exert different effects on oestrogen receptor function. British Journal of Cancer 80: 1150-1155. DOI 10.1038/sj.bjc.6690479.

Mortensen A, Kulling SE, Schwartz H, Rowland I, Ruefer CE, Rimbach G, Cassidy A, Magee P, Millar J, Hall WL, Birkved FK, Sorensen IK, Sontag G (2009). Analytical and compositional aspects of isoflavones in food and their biological effects. Molecular Nutrition \& Food Research 53: S266-S309. DOI 10.1002/mnfr.200800478.

Mumford S, Kim S, Chen Z, Boyd Barr D, Buck Louis GM (2015). Urinary phytoestrogens are associated with subtle indicators of semen quality among male partners of couples desiring pregnancy. Journal of Nutrition 145: 2535-2541. DOI 10.3945/jn.115.214973.

Murata M, Midorikawa K, Koh M, Umezawa K, Kawanishi S (2004). Genistein and daidzein induce cell proliferation and their 
metabolites cause oxidative DNA damage in relation to isoflavone-induced cancer of estrogen-sensitive organs. Biochemistry 43: 2569-2577. DOI 10.1021/bi035613d.

Nakamura Y, Ohsawa I, Goto Y, Tsuji M, Oguchi T, Sato N, Kiuchi Y, Fukumura M, Inagaki M, Gotoh H (2017). Soy isoflavones inducing overt hypothyroidism in a patient with chronic lymphocytic thyroiditis: A case report. Journal of Medical Case Reports 11: 489. DOI 10.1186/s13256-017-1418-9.

National Toxicology Program (1992). Toxicology and carcinogenesis studies of Quercetin (CAS No. 117-39-5) in F344 rats (Feed studies). National Toxicology Program Technical Report Series 409: 1-171.

Niedzwiecki A, Roomi MW, Kalinovsky T, Rath M (2016). Anticancer efficacy of polyphenols and their combinations. Nutrients 8: 552-568. DOI 10.3390/nu8090552.

Nimptsch K, Zhang X, Cassidy A, Song M, O’Reilly ÉJ, Lin JH, Pischon T, Rimm EB, Willett WC, Fuchs CS, Ogino S, Chan AT, Giovannucci EL, Wu K (2016). Habitual intake of flavonoid subclasses and risk of colorectal cancer in 2 large prospective cohorts. American Journal of Clinical Nutrition 103: 184-191. DOI 10.3945/ajcn.115.117507.

Pal S, Konkimalla VB (2016). Hormetic potential of sulforaphane (SFN) in switching cells' fate towards survival or death. Mini Reviews in Medicinal Chemistry 16: 980-995. DOI 10.2174/1389557516666151120115027.

Pandey A, Kaushik A, Wanjari M, Dey YN, Jaiswal BS, Dhodi A (2017). Antioxidant and anti-inflammatory activities of Aerva pseudotomentosa leaves. Pharmaceutical Biology 55: 1688-1697. DOI 10.1080/13880209.2017.1321022.

Papackova Z, Heczkova M, Dankova H, Sticova E, Lodererova A, Bartonova L, Poruba M, Cahova M (2018). Silymarin prevents acetaminophen-induced hepatotoxicity in mice. PLoS One 13: e0191353. DOI 10.1371/journal.pone.0191353.

Persiani S, Sala F, Manzotti C, Colovic M, Zangarini M, Donazzolo Y, Barbetta B, Vitalini C, Giacovelli G, Benvenuti C, Rovati L (2016). Evaluation of levothyroxine bioavailability after oral administration of a fixed combination of soy isoflavones in post-menopausal female volunteers. Drug Research 66: 136-140. DOI 10.1055/s-0035-1555784.

Piccolo BD, Mercer KE, Bhattacharyya S, Bowlin AK, Saraf MK, Pack L, Chintapalli SV, Shankar K, Adams SH, Badger TM, Yeruva L (2017). Early postnatal diets affect the bioregional small intestine microbiome and ileal metabolome in neonatal pigs. Journal of Nutrition 147: 1499-1509. DOI 10.3945/ jn.117.252767.

Rasheed NOA, Ahmed LA, Abdallah DM, El-Sayeh BM (2017). Nephro-toxic effects of intraperitoneally injected EGCG in diabetic mice: Involvement of oxidative stress, inflammation and apoptosis. Scientific Reports 7: 265. DOI 10.1038/srep40617.

Reed KE, Camargo J, Hamilton-Reeves J, Kurzer M, Messina M (2021). Neither soy nor isoflavone intake affects male reproductive hormones: An expanded and updated metaanalysis of clinical studies. Reproductive Toxicology 100: 60-67. DOI 10.1016/j.reprotox.2020.12.019.

Renko K, Schäche S, Hoefig CS, Welsink T, Schwiebert C, Braun D, Becker NP, Köhrle J, Schomburg L (2015). An improved nonradioactive screening method identifies genistein and xanthohumol as potent inhibitors of iodothyronine deiodinases. Thyroid 25: 962-968. DOI 10.1089/thy.2015.0058.

Rietjens IM, Boersma MG, van der Woude H, Jeurissen SM, Schutte ME, Alink GM (2005). Flavonoids and alkenylbenzenes: Mechanisms of mutagenic action and carcinogenic risk.
Mutation Research 574: 124-138. DOI 10.1016/j. mrfmmm.2005.01.028.

Rimoldi G, Christoffel J, Seidlova-Wuttke D, Jarry H, Wuttke W (2007). Effects of chronic genistein treatment in mammary gland, uterus, and vagina. Environmental Health Perspectives 115: 62-68. DOI 10.1289/ehp.9367.

Rizzo G, Baroni L (2018). Soy, soy foods and their role in vegetarian diets. Nutrients 10: 43-93. DOI 10.3390/nu10010043.

Robertson KM, O’Donnell L, Simpson ER, Jones MEE (2002). The phenotype of the aromatase knockout mouse reveals dietary phytoestrogens impact significantly on testis function. Endocrinology 143: 2913-2921. DOI 10.1210/ endo.143.8.8957.

Rodriguez-Gomez A, Filice F, Gotti S, Panzica G (2014). Perinatal exposure to genistein affects the normal development of anxiety and aggressive behaviors and nitric oxide system in CD1 male mice. Physiology \& Behavior 133: 107-114. DOI 10.1016/j.physbeh.2014.05.020.

Rosenfeld CS (2015). Microbiome disturbances and autism spectrum disorders. Drug Metabolism and Disposition 43: 1557-1571. DOI 10.1124/dmd.115.063826.

Ronis MJJ, Gomez H, Shankar K, Sharma N, Blackburn M, Singhal R, Mercer KE, Badger TM (2018). Soy protein isolate feeding does not result in reproductive toxicity in the pre-pubertal rat testis. Experimental Biology and Medicine 243: 695-707. DOI 10.1177/1535370218771333.

Santos MA, Florencio-Silva R, Teixeira CP, Sasso GR, Marinho DS, Simões RS, Simões MJ, Carbonel AF (2016). Effects of early and late treatment with soy isoflavones in the mammary gland of ovariectomized rats. Climacteric 19: 77-84. DOI 10.3109/13697137.2015.1094783.

Sathyapalan T, Manuchehri AM, Thatcher NJ, Rigby AS, Chapman T, Kilpatrick ES, Atkin SL (2011). The effect of soy phytoestrogen supplementation on thyroid status and cardiovascular risk markers in patients with subclinical hypothyroidism: A randomized, double-blind, crossover study. Journal of Clinical Endocrinology \& Metabolism 96: 1442-1449. DOI 10.1210/jc.2010-2255.

Sharpe RM, Martin B, Morris K, Greig I, McKinnell C, McNeilly AS, Walker M (2002). Infant feeding with soy formula milk: effects on the testis and on blood testosterone levels in marmoset monkeys during the period of neonatal testicular activity. Human Reproduction 17: 1692-1703. DOI 10.1093/humrep/17.7.1692.

Silverstein MG, Kaplan JR, Appt SE, Register TC, Shively CA (2014). Effect of soy isoflavones on thyroid hormones in intact and ovariectomized cynomolgus monkeys (Macaca fascicularis). Menopause-Journal of the North American Menopause Society 21: 1136-1142. DOI 10.1097/GME.0000000000000223.

Singh B, Mense SM, Bhat NK, Putty S, Guthiel WA, Remotti F, Bhat HK (2010). Dietary quercetin exacerbates the development of estrogen-induced breast tumors in female ACI rats. Toxicology and Applied Pharmacology 247: 83-90. DOI 10.1016/j.taap.2010.06.011.

Smith-Brown P, Morrison M, Krause ML, Davies PSW (2016). Dairy and plant based food intakes are associated with altered faecal microbiota in 2 to 3 year old Australian children. Scientific Reports 6: 32385. DOI 10.1038/srep32385.

Smith BN, Oelschlager ML, Abdul Rasheed MS, Dilger RN (2020). Dietary soy isoflavones reduce pathogen-related mortality in growing pigs under porcine reproductive and respiratory syndrome viral challenge. Journal of Animal Science 98: 49. DOI 10.1093/jas/skaa024. 
Šošić-Jurjević B, Filipović B, Wirth EK, Živanović J, Radulović N, Janković S, Milošević V, Köhrle J (2014). Soy isoflavones interfere with thyroid hormone homeostasis in orchidectomized middle-aged rats. Toxicology and Applied Pharmacology 278: 124-134. DOI 10.1016/j. taap.2014.04.018.

Šošić-Jurjević B, Lütjohann D, Jarić I, Miler M, Vojnović Milutinović D, Filipović B, Ajdžanović V, Renko K, Wirth EK, Janković S, Köhrle J, Milošević V (2017). Effects of age and soybean isoflavones on hepatic cholesterol metabolism and thyroid hormone availability in acyclic female rats. Experimental Gerontology 92: 74-81. DOI 10.1016/j.exger.2017.03.016.

Strom BL, Schinnar R, Ziegler EE, Barnhart KT, Sammel MD, Macones GA, Stallings VA, Drulis JM, Nelson SE, Hanson SA (2001). Exposure to soy-based formula in infancy and endocrinological and reproductive outcomes in young adulthood. JAMA 286: 807-814. DOI 10.1001/jama.286.7.807.

Sudo N, Chida Y, Aiba Y, Sonoda J, Oyama N, Yu XN, Kubo C, Koga $Y$ (2004). Postnatal microbial colonization programs the hypothalamic-pituitary-adrenal system for stress response in mice. Journal of Physiology 558: 263-275. DOI 10.1113/ jphysiol.2004.063388.

Swezey RR, Aldridge DE, LeValley SE, Crowell JA, Hara Y, Green CE (2003). Absorption, tissue distribution and elimination of 4$\left[{ }^{3} \mathrm{H}\right]$-epigallocatechin gallate in beagle dogs. International Journal of Toxicology 22: 187-193. DOI 10.1080/10915810305101.

Szczechowiak K, Diniz BS, Leszek J (2019). Diet and Alzheimer's dementia-Nutritional approach to modulate inflammation. Pharmacology Biochemistry and Behavior 184: 172743. DOI 10.1016/j.pbb.2019.172743.

Tan KAL, Walker M, Morris K, Greig I, Mason JI, Sharpe RM (2006). Infant feeding with soy formula milk: Effects on puberty progression, reproductive function and testicular cell numbers in marmoset monkeys in adulthood. Human Reproduction 21: 896-904. DOI 10.1093/humrep/dei421.

Tonstad S, Jaceldo-Siegl K, Messina M, Haddad E, Fraser GE (2016). The association between soya consumption and serum thyroid-stimulating hormone concentrations in the Adventist Health Study-2. Public Health Nutrition 19: 1464-1470. DOI 10.1017/S1368980015002943.

van der Woude H, Alink GM, van Rossum BE, Walle K, van Steeg H, Walle T, Rietjens IM (2005). Formation of transient covalent protein and dna adducts by quercetin in cells with and without oxidative enzyme activity. Chemical Research in Toxicology 18: 1907-1916. DOI 10.1021/tx050201m.

Vázquez L, Flórez AB, Guadamuro L, Mayo B (2017). Effect of soy isoflavones on growth of representative bacterial species from the human gut. Nutrients 9: 727-736. DOI 10.3390/ nu9070727.

Volobuff CRF, Pederiva MMC, Benites RSR, Lima CJ, Argandoña EJS, Cardoso CAL, Pereira ZV, Ruiz ALTG, Foglio MA, de Carvalho JE, Formagio ASN (2019). Bioguided fractionation, and antioxidant, antiproliferative, and antiinflammatory activity of annona cacans warm. Journal of Medicinal Food 22: 1078-1086. DOI 10.1089/jmf.2018.0198.

Wang D, Wang Y, Wan X, Yang CS, Zhang J (2015). Green tea polyphenol (-)-epigallocatechin-3-gallate triggered hepatotoxicity in mice: Responses of major antioxidant enzymes and the Nrf2 rescue pathway. Toxicology and Applied Pharmacology 283: 65-74. DOI 10.1016/j.taap.2014.12.018.

West MCL, Anderson L, McClure N, Lewis SEM (2005). Dietary oestrogens and male fertility potential. Human Fertility 8: 197-207. DOI 10.1080/14647270500030266.
Wisniewski AB, Cernetich A, Gearhart JP, Klein SL (2005). Perinatal exposure to genistein alters reproductive development and aggressive behavior in male mice. Physiology \& Behavior 84: 327-334. DOI 10.1016/j.physbeh.2004.12.008.

Westmark CJ (2013). Soy infant formula may be associated with autistic behaviors. Autism 3: 20727.

Westmark CJ (2014). Soy infant formula and seizures in children with autism: A retrospective study. PLoS One 9: e80488. DOI 10.1371/journal.pone.0080488.

Wu GD, Compher C, Chen EZ, Smith SA, Shah RD, Bittinger K, Chehoud C, Albenberg LG, Nessel L, Gilroy E, Star J, Weljie AM, Flint HJ, Metz DC, Bennett MJ, Li H, Bushman FD, Lewis JD (2016). Comparative metabolomics in vegans and omnivores reveal constraints on diet-dependent gut microbiota metabolite production. Gut 65: 63-72. DOI 10.1136/gutjnl-2014-308209.

Wu Q, Kroon PA, Shao H, Needs PW, Yang X (2018). Differential effects of quercetin and two of its derivatives, isorhamnetin and isorhamnetin-3-glucuronide, in inhibiting the proliferation of human breast-cancer MCF-7 cells. Journal of Agricultural and Food Chemistry 66: 7181-7189. DOI 10.1021/acs.jafc.8b02420.

Wyns C, Bolca S, De Keukeleire D, Heyerick A (2010). Development of a high-throughput LC/APCI-MS method for the determination of thirteen phytoestrogens including gut microbial metabolites in human urine and serum. Journal of Chromatography B 878: 949-956. DOI 10.1016/j.jchromb.2010.02.022.

Xiao Q, Park Y, Hollenbeck AR, Kitahara CM (2014). Dietary flavonoid intake and thyroid cancer risk in the NIH-AARP diet and health study. Cancer Epidemiology Biomarkers \& Prevention 23: 11021108. DOI 10.1158/1055-9965.EPI-13-1150.

Yatkin E, Streng T, Kauppila ML, Bernoulli J, Saarinen N, Santti R (2007). The soy effect in the disease models of nonbacterial prostatitis and obstructive voiding. Experimental Biology \& Medicine 232: 674-681.

Yeruva L, Spencer NE, Saraf MK, Hennings L, Bowlin AK, Cleves MA, Mercer K, Chintapalli SV, Shankar K, Rank RG, Badger TM, Ronis MJ (2016). Formula diet alters small intestine morphology, microbial abundance and reduces VE-cadherin and IL-10 expression in neonatal porcine model. BMC Gastroenterology 16: 39A. DOI 10.1186/ s12876-016-0456-x.

Ying C, Hsu JT, Hung HC, Lin DH, Chen LF, Wang LK (2002). Growth and cell cycle regulation by isoflavones in human breast carcinoma cells. Reproduction Nutrition Development 42: 55-64. DOI 10.1051/rnd:2002006.

Yoshikata R, Myint KZ, Ohta H, Ishigaki Y (2019). Inter-relationship between diet, lifestyle habits, gut microflora, and the equolproducer phenotype: Baseline findings from a placebocontrolled intervention trial. Menopause-the Journal of The North American Menopause Society 26: 273-285. DOI 10.1097/GME.0000000000001202.

Zhang P, Kishimoto Y, Grammatikakis I, Gottimukkala K, Cutler RG, Zhang S, Abdelmohsen K, Bohr VA, Sen JM, Gorospe M, Mattson MP (2019). Senolytic therapy alleviates A $\beta$ associated oligodendrocyte progenitor cell senescence and cognitive deficits in an Alzheimer's disease model. Nature Neuroscience 22: 719-728. DOI 10.1038/s41593-019-0372-9.

Zhang Q, Chen D, Yu B, Mao X, Huang Z, Yu J, Luo J, Zheng P, Luo $Y$, He J (2018). Effects of dietary daidzein supplementation on reproductive performance, serum hormones, and reproductive-related genes in rats. Nutrients 10: 766-778. DOI 10.3390/nu10060766. 
Zhao TT, Jin F, Li JG, Xu YY, Dong HT, Liu Q, Xing P, Zhu GL, Xu H, Miao ZF (2019). Dietary isoflavones or isoflavone-rich food intake and breast cancer risk: A meta-analysis of prospective cohort studies. Clinical Nutrition 38: 136-145. DOI 10.1016/j.clnu.2017.12.006.

Zhu BT, Liehr JG (1994). Quercetin increases the severity of estradiol-induced tumorigenesis in hamster kidney.
Toxicology and Applied Pharmacology 125: 149-158. DOI 10.1006/taap.1994.1059.

Zou H, Wang S, Liu Y, Mo J, Yang L, Zhao Y, Yi P, Niu L, Huang Y, Lu Y (2020). The effect of hormonal levels and oxidative stress on bisphenol A and soy isoflavone reproductive toxicity in murine offspring. Molecular Medicine Reports 22: 4938-4946. DOI 10.3892/mmr.2020.11544. 